\title{
Pembuatan peta photo udara Desa Wonosari menggunakan UAV Fixed Wing
}

\author{
Hendra Saputra*, \& Armada \\ Politeknik Negeri Bengkalis \\ *hendrasaputramsc@gmail.com
}

\begin{abstract}
Abstrak. Desa wonosari memiliki sumber daya alam seperti pertanian, perkebunan dan pariwisata. Di sektor perkebunan seperti kelapa sawit dan karet. Di sektor pariwisata Desa Wonosari memiliki kawasan hutan yang cukup luas untuk dijadikan daya tarik desa tersebut seperti hutan alam, tempat outbound, sebagai tempat perkemahan, dan waduk/situ. Untuk memaksimalkan potensi tersebut dibutuhkan perencanaan yang matang yang komprehensif. Tujuan kegiatan pengabdian ini adalah untuk melakukan pemetaan foto udara dengan menggunakan UAV di Desa Wonosari. Peta photo udara skala besar adalah solusi untuk dijadikan pedoman dalam penentuan dan pembuat kebijakan. Pada kegiatan pengabdian ini metode yang digunakan adalah pemanfaatan Drone/UAV Fixed wing. Hasil dari kegiatan pengabdian ini berupa foto udara orthophoto dengan luasan $1577 \mathrm{Ha}$. Keunggulan peta photo udara adalah kenampakan objek secara nyata dengan resolusi tinggi. Pemerintah desa bisa memanfaatkan peta photo udara ini untuk menentukan batas administrasi desa, batas rukun tetangga dan rukun warga, pedoman dalam pembuatan masterplan serta sebagai data pendukung dalam menentukan profil desa.
\end{abstract}

Kata kunci: peta foto udara, UAV Fixed Wing

\begin{abstract}
Wonosari Village has natural resources such as agriculture, plantations and tourism. Plantation sector such as oil palm and rubber. In the tourism sector, Wonosari Village has forest areas that are wide enough to be used as an attraction for the village, such as natural forests, outbound places, as campsites, and reservoirs/lakes. To maximize this potential, it takes careful and comprehensive planning. Large-scale aerial images maps are a solution to serve as guidelines in determining and policymakers. In these activities, the method used is the use of UAV Fixed Wing. The results are in the form of orthophoto aerial imagery with an area of 1577 hectares. The advantage of aerial photo maps is the real appearance of objects with high resolution. The village government can use this aerial photo map to determine village administrative boundaries, "rukun tetangga" and "rukun warga" boundaries, guidelines in making master plans as well as supporting data in determining village profiles.
\end{abstract}

Keywords: aerial imagery, Fixed Wing UAV

To cite this article: Saputra, H., \& Armada. 2020. Pembuatan peta photo udara Desa Wonosari menggunakan UAV Fixed Wing. Unri Conference Series: Community Engagement 2: 423-431. https://doi.org/10.31258/unricsce.2.423$\underline{431}$

\section{(C) 2020 Authors}

Peer-review under responsibility of the organizing committee of Seminar Nasional Pemberdayaan Masyarakat 2020 


\section{PENDAHULUAN}

Secara Geografis Desa Wonosari adalah salah satu desa yang yang secara administratif berada di Kecamatan Bengkalis, Kabupaten Bengkalis. Desa wonosari berbatasan dengan desa jangkang di sebelah utara, Kelurahan Bengkalis Kota di sebelah selatan, Desa Senggoro di sebelah timur dan Desa Pedekik di sebelah barat. Desa Wonosari memiliki sumber daya alam seperti pertanian, perkebunan dan pariwisata. Sektor perkebunan seperti kelapa sawit dan karet. Di sektor pariwisata Desa Wonosari memiliki kawasan hutan yang cukup luas untuk dijadikan daya tarik desa tersebut seperti hutan alam, tempat outbound, sebagai tempat perkemahan, dan waduk/situ. Potensi-potensi tersebut belum tertata dengan baik dan dan belum adanya master plan/blue-print . Secara spesifik permasalahan-permasalahan Desa Wonosari sebagai berikut:

1. Belum adanya peta photo udara Desa Wonosari secara keseluruhan. Berdasarkan hasil kunjungan ke Desa Wonosari yang mana desa tersebut belum memiliki peta photo udara dan hanya memiliki peta garis yang tidak tergeoreferensi (tidak memiliki koordinat). Peta photo udara merupakan data pendukung utama untuk pembuatan master plan Desa Wonosari.

2. Ketidakjelasan batas antar desa bersebelahan.

3. Belum memiliki Batas kawasan RT dan RW yang terintegrasi dengan peta dan

4. Belum memiliki rencana induk (master plan) Desa Wonosari

\section{METODE PENERAPAN}

Metode pelaksanaan terbagi dalam 4(empat) tahapan utama yaitu persiapan data, akuisisi data, pemodelan dan pembuatan basis data, dan penyajian peta desa. Adapun Adapun tahapan-tahapan dalam penelitian ini disajikan dalam bagan alir berikut:

1. Persiapan penelitian meliputi: studi literatur, persiapan peralatan, bahan dan data sekunder (peta administrasi desa), perijinan pengambilan data lapangan ke pemerintah Desa Kelapapati.

2. Persiapan data GCP meliputi: perencanaan batasan wilayah terbang atau Area of Interest (AOI), perencanaan sebaran dan titik GCP dan ICP dengan menggunakan aplikasi Google Earth, pemasangan patok titik kontrol GCP dan ICP di lapangan, pengukuran koordinat GCP dan ICP menggunakan GPS Geodetik.

3. Pembuatan jalur terbang dengan menggunakan Aplikasi Mission Planner. Perencanaan jalur terbang harus memperhatikan ketinggian terbang, pertampalan antara foto (sidelap/frontlap), kecepatan, kecerahan, lokasi, dan kondisi angin.

4. Pemotretan foto udara dengan menggunakan UAV.

5. Pengolahan data

6. Pembentukan orthomosaic

7. Pembentukan DEM

8. Pemodelan 3D

9. Pembuatan database SIG

10. Uji ketelitian peta 


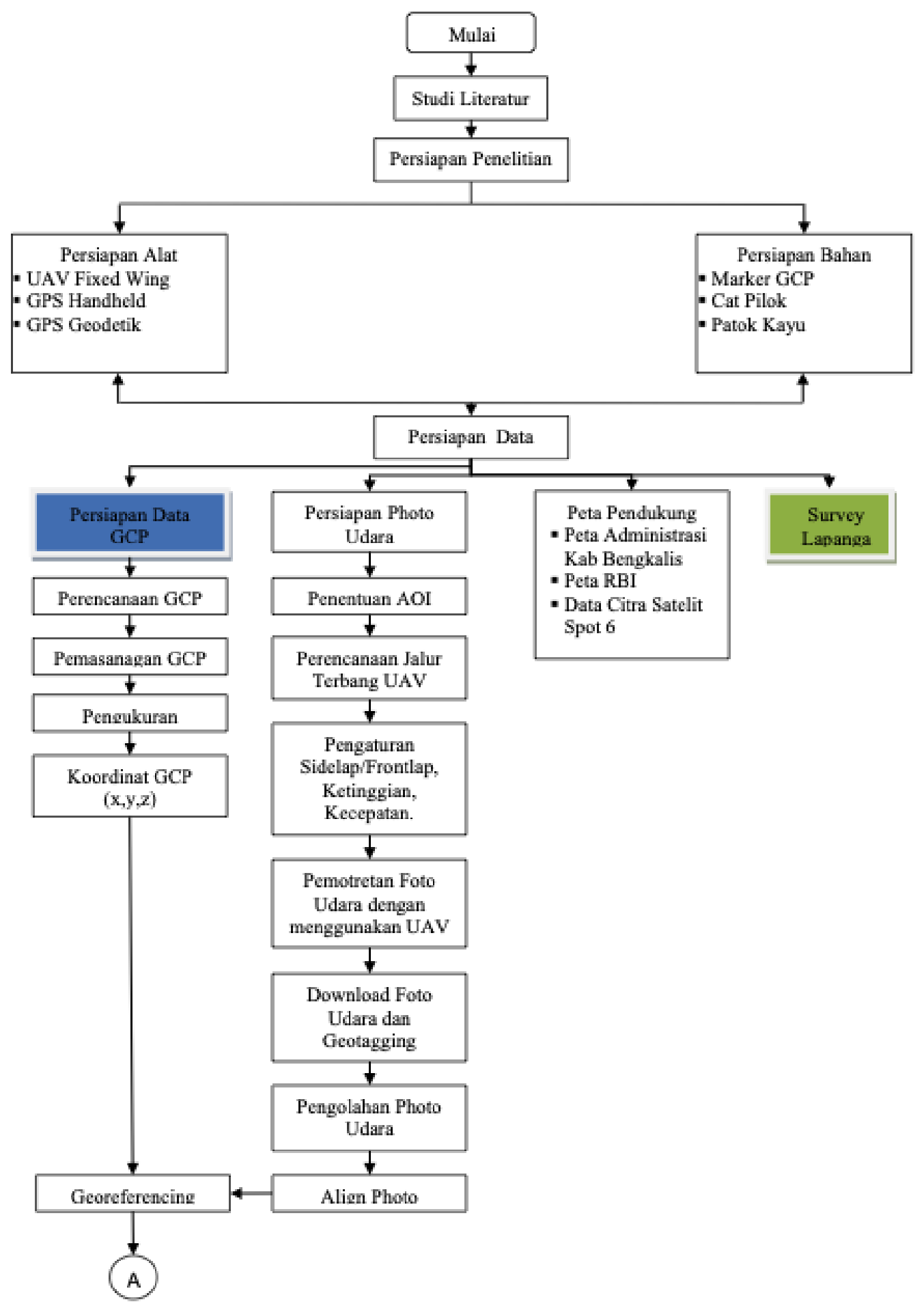




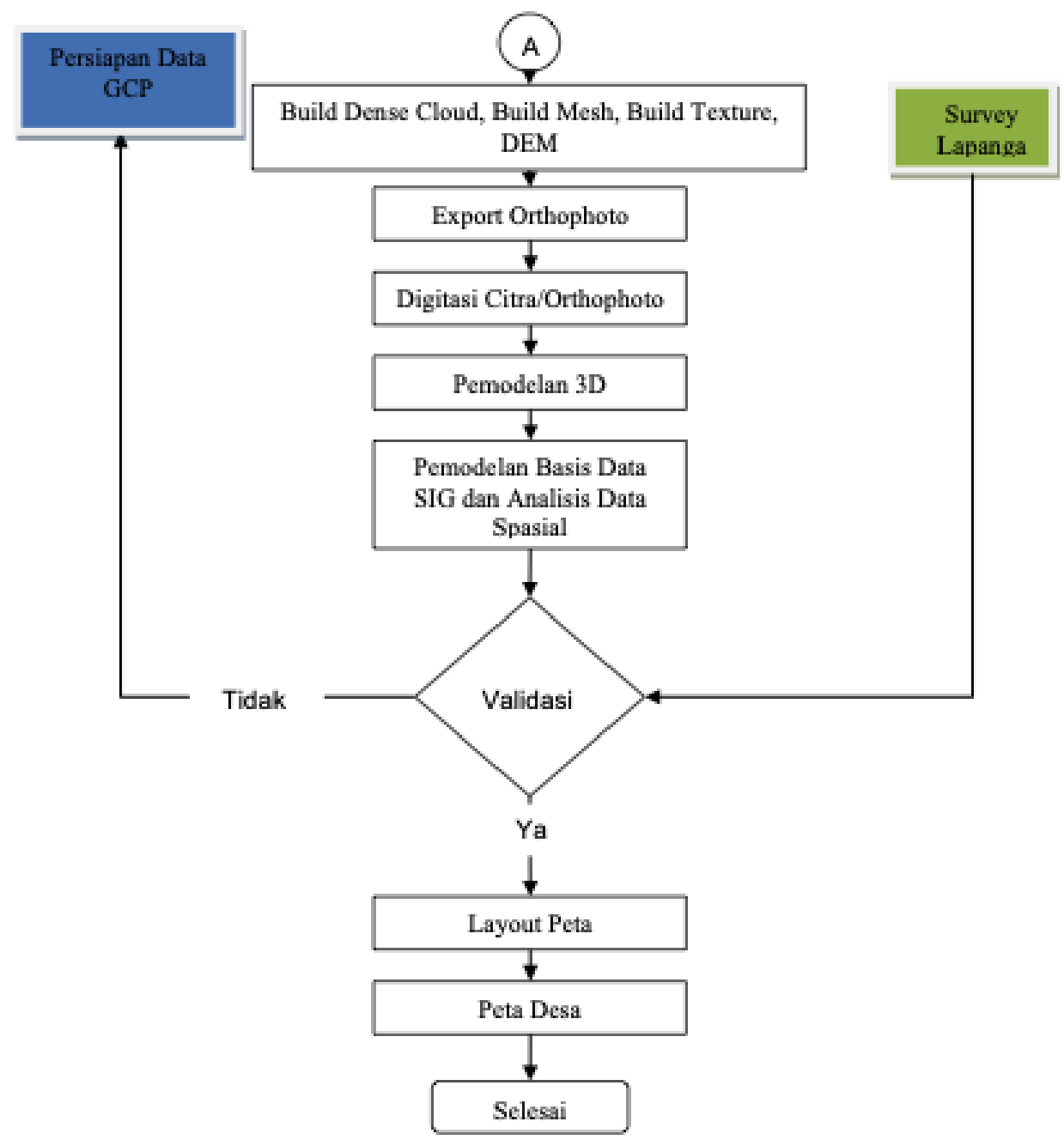

Gambar 1. Bagan Alir Kegiatan

\section{HASIL DAN KETERCAPAIAN SASARAN}

Kegiatan pengabdian ini dilaksanakan di Desa Wonosari Kecamatan Bengkalis. Kegiatan pengabdian ini berupa pemetaan foto udara dengan menggunakan wahana tanpa awak atau lebih sering dikenal dengan Drone/UAV. Luas area pemotretan 1577 Ha. Tahapan pelaksanaan kegiatan ini meliputi: koordinasi dengan pihak desa untuk memperoleh informasi terkait luasan Desa Wonosari, penentuan titik ikat control point atau GCP (ground control point), pengukuran koordinat GCP dengan menggunakan GPS Geodetik Trimble R8S, Pembuatan Misi Terbang, Akuisisi data menggunakan UAV, dan pengolahan data (layout Peta). Berikut hasil capaian kegiatan pengabdian di Desa Wonosari.

\section{Hasil Pengukuran Titik Ikat Tanah/Ground Control Point}

Pengukuran koordinat titik ikat GCP menggunakan GPS Geodetik Trimble R8S. sebaran titik ikat GCP terdistribusi merata sesuai dengan luas kawasan pemetaan dengan jumlah titik ikatnya sebanyak 9 titik dan 1 titik untuk Benchmarking (BM). 


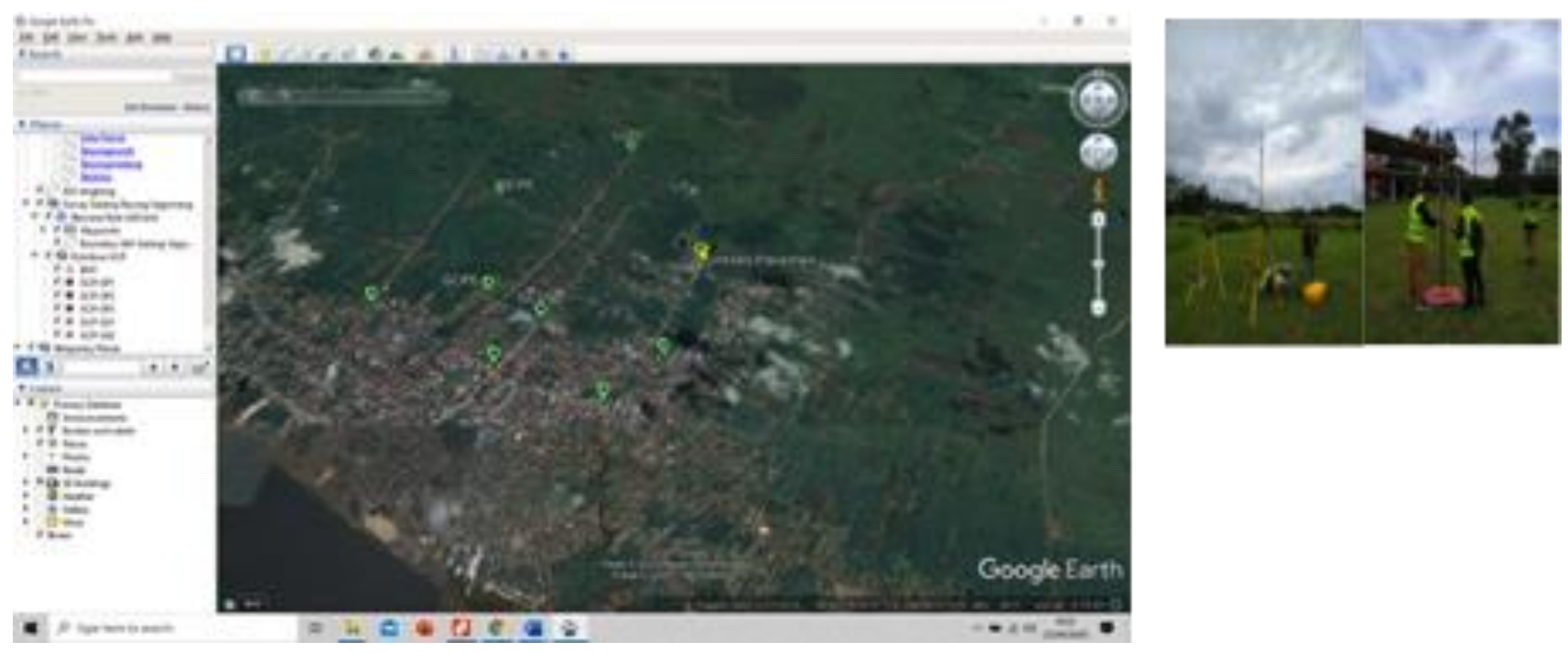

Gambar 2. Pengukuran Titik Ikat GCP Menggunakan GPS Geodetik Trimble R8s

Tabel 1. Koordinat Titik Ikat GCP (UTM, Zone 48N)

\begin{tabular}{clccc}
\hline No & Keterangan & Easting $(\mathrm{x})$ & Northing $(\mathrm{y})$ & Elevasi (z) \\
\hline 1 & BM & 180418,732 & 165163,575 & 5,122 \\
2 & GCP 1 & 180408,195 & 165157,326 & 5,139 \\
3 & GCP 2 & 180090,829 & 164043,982 & 3,666 \\
4 & GCP 3 & 179617,882 & 163313,584 & 3,85 \\
5 & GCP 4 & 178725,989 & 163832,555 & 4,106 \\
6 & GCP 5 & 179114,899 & 164241,630 & 4,926 \\
7 & GCP 6 & 178581,279 & 164488,713 & 6,409 \\
8 & GCP 7 & 177585,579 & 164554,732 & 5,217 \\
9 & GCP 8 & 178491,137 & 165904,162 & 9,487 \\
10 & GCP 9 & 179727,095 & 166622,052 & 9,280 \\
\hline
\end{tabular}

\section{Akuisisi Menggunakan UAV Fixed Wing}

Pemotretan photo udara menggunakan UAV Fixed Wing. Misi terbang dilakukan sebelum pemotretan udara dilakukan. Misi terbang dibuat dengan menggunakan Software Mission Planner. Jumlah misi terbang sebanyak 6 Misi. Durasi atau lamanya terbang UAV Fixed Wing tergantung dari kapasitas Baterainya. Pada kegiatan pengabdian ini setiap misi terbang memiliki luas sebesar $300 \mathrm{Ha}$ dengan durasi (endurance) terbang 30-50 Menit/misi terbang tergantung kondisi cuaca. 

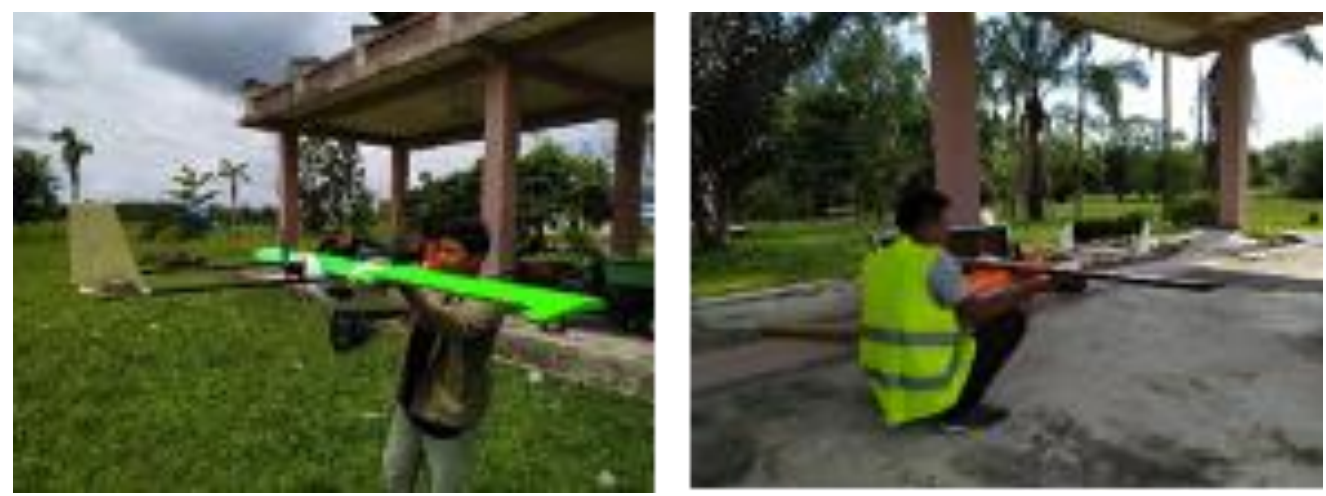

Gambar 3. UAV Fixed Wing

Setelah pemotretan photo udara, langkah selanjutnya adalah mendowload foto udara dan geotagging photo udara supaya memiliki koordinat.

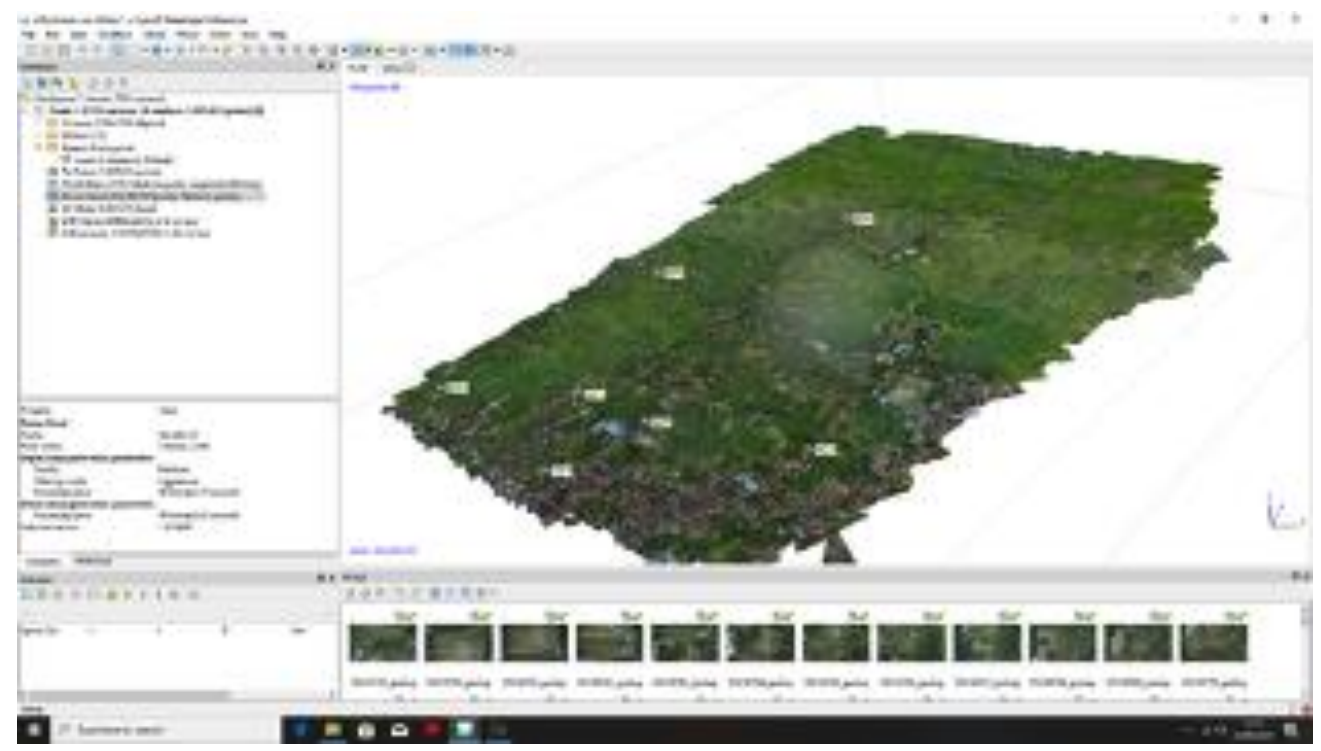

Gambar 4. Dense Cloud

\section{KESIMPULAN}

Pemanfaatan Drone/UAV khususnya jenis fixed wing sangat efektif dan efisien dalam pemetaan skala besar. Luas area pemotretan 1577 Ha dengan jumlah misi terbang 6 misi. Peta photo udara bisa dijadikan pedoman oleh pemerintah desa wonosari dalam mengambil kebijakan.

Hasil dari peta photo udara ini bisa dijadikan sebagai basemap untuk pembuatan GIS (Geographic Information System). Kedepannya pihak desa bisa melakukan penyusunan data profil desa berbasis GIS.

\section{UCAPAN TERIMA KASIH}

Tim penulis mengucapkan terima kasih kepada Pusat Penelitian dan Pengabdian Pada Masyarakat (P3M) Politeknik Negeri Bengkalis yang telah memfasilitasi pengabdian ini, Pemerintah Desa Wonosari, Pak Mariandi (andi) selaku pilot UAV dan Tim Kerja yang solid sehingga terselenggaranya kegiatan pengabdian ini.

\section{DAFTAR PUSTAKA}

Badan Informasi Geospasial. 2014. Peraturan Kepala BIG no. 14 tahun 2014 tentang Pedoman teknis ketelitian peta dasar. Badan Informasi Geospasial, Cibinong, Bogor.

Badan Informasi Geospasial. 2020. Peraturan Kepala BIG Republik Indonesia Nomor 1 Tahun 2020 Tentang Standar Pengumpulan Data Geospasial Dasar Untuk Pembuatan Peta Dasar Skala Besar. Badan Informasi Geospasial, Cibinong, Bogor 
Husna, S. N., Subiyanto, S., \& Hani'ah. 2016. Penggunaan Parameter Orientasi Eksternal (EO) Untuk Optimalisasi Digital Triangulasi Fotogrametri. Jurnal Geodesi Undip, 5(4).

Noor Rahmadan P Mahardika., dkk. 2019. Pemanfaatan Teknologi UAV (Unmanned Aerial Vehicle) Untuk Pengumpulan Data Geospasial. Prosiding Seminar Nasional Pendidikan Geografi FKIP UMP "Manajemen Bencana di Era Revolusi Industri 5.0” ISBN 978-602-6697-38-7.10 Agustus 2019. Purwokerto

Syahza, A. 2004. Pemberdayaan Ekonomi Masyarakat Pedesaan melalui Pengembangan Industri Hilir Berbasis Kelapa Sawit di Daerah Riau. Disertasi Program Doktor. Universitas Padjadjaran.

Undang-undang Nomor 4 tahun 2011 tentang informasi geospasial (IG) 
Lampiran I (Peta Photo Udara Desa Wonosari Kecamatan Bengkalis, Kab. Bengkalis)

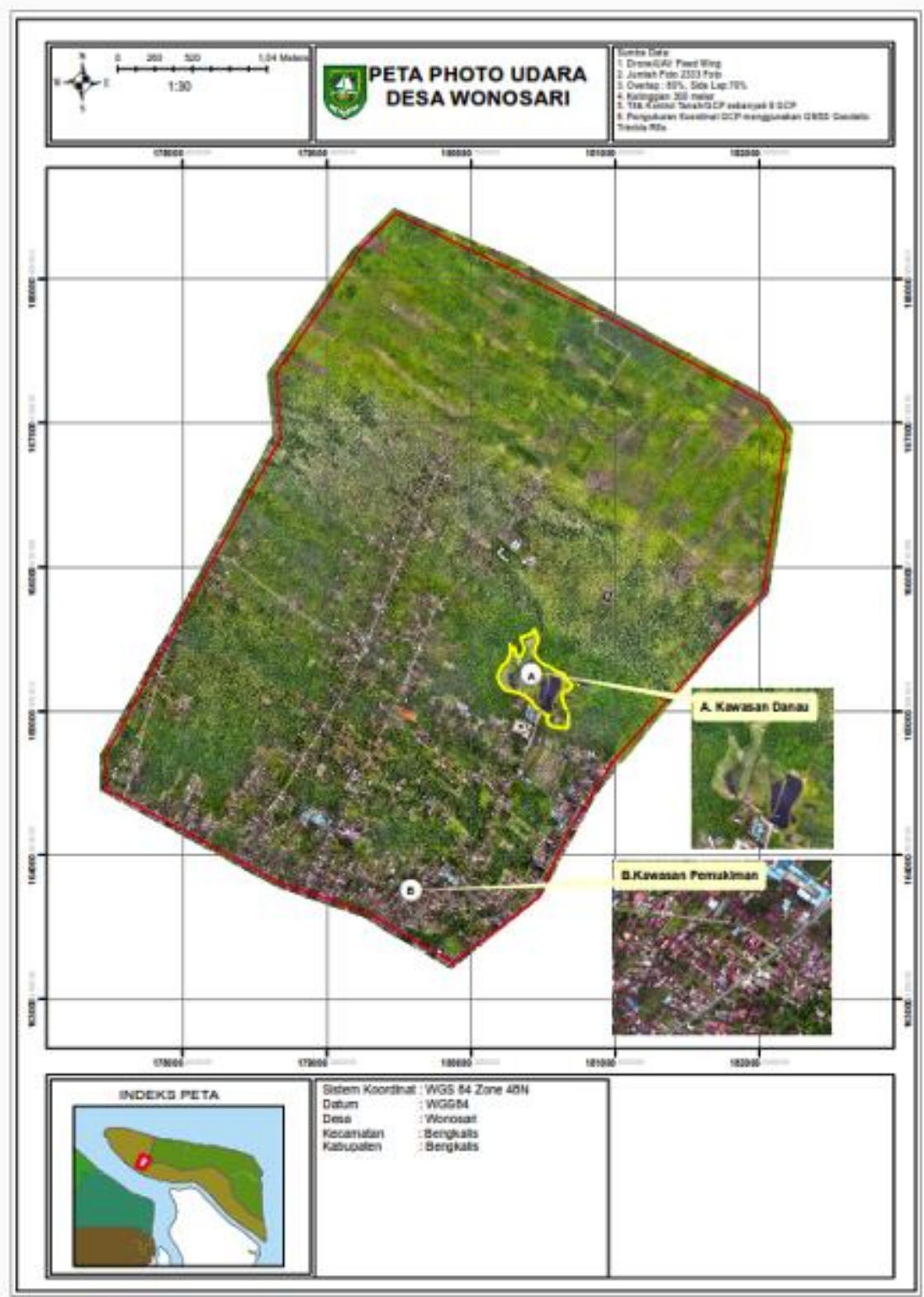


Lampiran II (Integrasi Photo Udara dan SIG)

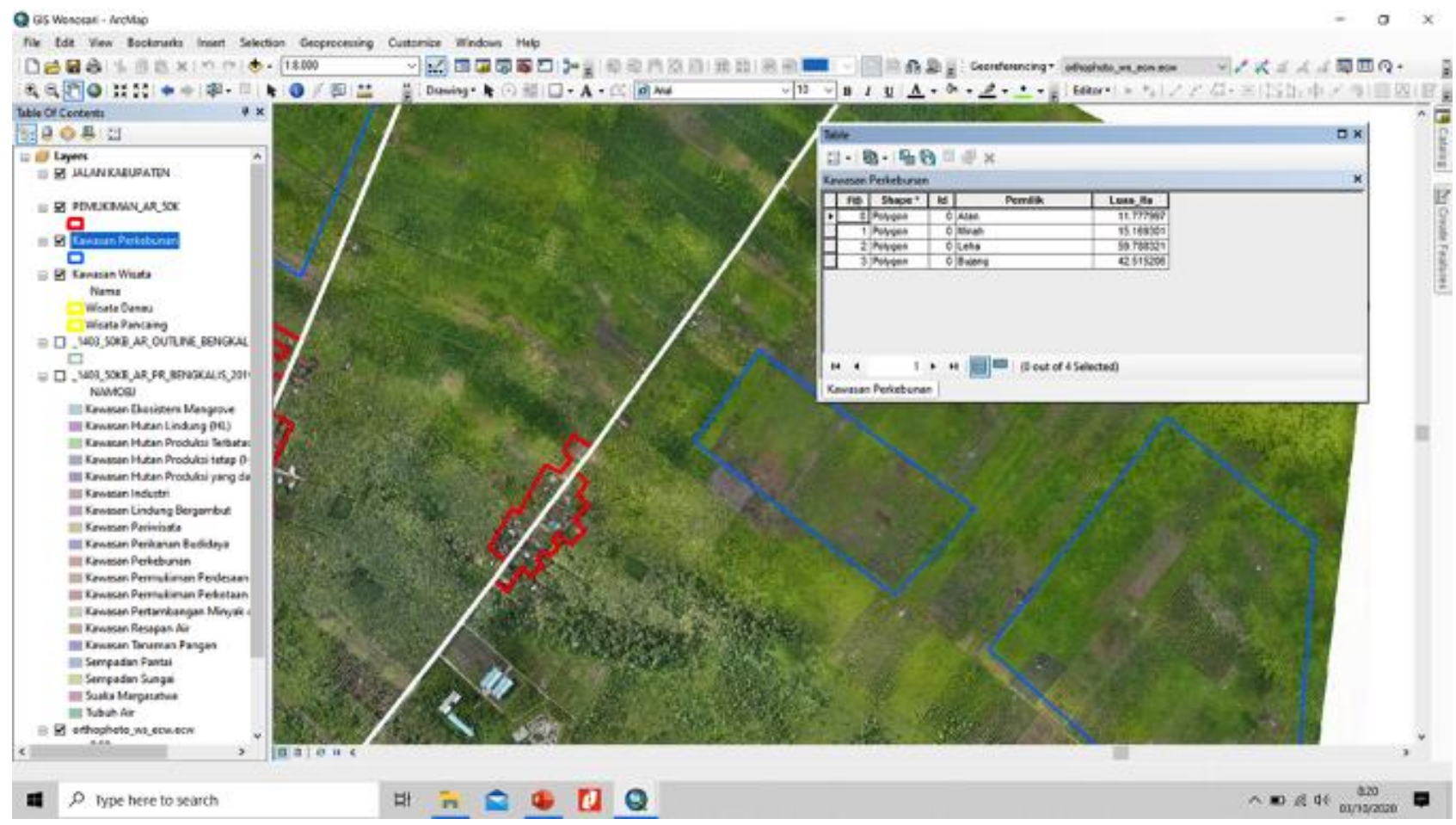

